\title{
Opioid Doses and Acute Care Utilization Outcomes for Adults with Sickle Cell Disease: Emergency Department versus Acute Care Unit
}

Robert E. Molokie, MD ${ }^{\mathrm{a}, \mathrm{b}, \mathrm{c},}$; Chariz Montminy, BSN, RN ${ }^{\mathrm{d}}$; Corissa Dionisio, MD ${ }^{\mathrm{e}}$; Muhammad Ahmen Farooqui, MsC ; Michel Gowhari, $\mathrm{DO}^{\mathrm{a}}$; Yingwei Yao, $\mathrm{PhD}^{\mathrm{g}, \mathrm{h}}$; Marie L. Suarez, $\mathrm{PhD}^{\mathrm{g}}$; Miriam O. Ezenwa, PhD, RN ${ }^{\mathrm{g}, \mathrm{h}}$; Judith M. Schlaeger, PhD, CNM, LAc ; Zaijie J. Wang, PhD ${ }^{\text {c }}$; Diana J. Wilkie, PhD, RN, FAAN ${ }^{\mathrm{g}, \mathrm{h}}$

${ }^{a}$ University of Illinois at Chicago College of Medicine Department of Hematology/Oncology, 820 S. Wood Street Suite 172 CSN (M/C 712), Chicago, IL 60612, remolokie@uic.edu, mgowhal@uic.edu

${ }^{\mathbf{b}}$ Jesse Brown Veterans Administration Medical Center, 820 S. Damen Avenue, MP 111 Chicago, IL 60612

${ }^{\mathbf{c}}$ University of Illinois at Chicago College of Pharmacy Department of Biopharmaceutical Sciences, 833 S. Wood Street, Chicago, IL 60612, zjwang@uic.edu

${ }^{\mathrm{d}}$ University of Illinois Hospital and Health Sciences System Department of Nursing, $1740 \mathrm{~W}$. Taylor, Chicago, IL 60614, ccalip2@uic.edu

${ }^{\mathrm{e}}$ Riley Hospital for Children at Indiana University Health Department of Psychiatry, 705 Riley Hospital Drive, Indianapolis, IN 46202, cdionisio@iu.edu

${ }^{\mathrm{f}}$ Saint George's University, University Centre, Grenada, West Indies, ahmed.farooqui4@gmail.com

${ }^{\mathrm{g}}$ University of Illinois at Chicago College of Nursing Department of Biobehavioral Health Science, 845 S. Damen Avenue, (M/C 802) Chicago, IL 60612, yyao@uic.edu, mlsuarez@uic.edu, moezenwa@uic.edu, diwilkie@uic.edu

${ }^{\mathrm{h}}$ University of Florida College of Nursing Department of Biobehavioral Nursing Science, 1225 Center Drive, Room 2203, Gainesville, FL 32610, y.yao@ufl.edu, moezenwa@ufl.edu, diwilkie@ufl.edu

${ }^{\mathrm{i}}$ University of Illinois at Chicago College of Nursing Department of Women, Children and Family Health Science, 845 S. Damen Avenue, (M/C 802) Chicago, IL 60612, jschlaeg@uic.edu 
Corresponding author:

Robert E. Molokie, MD

Assistant Professor

University of Illinois at Chicago, College of Medicine Department of Medicine, Division of Hematology/Oncology College of Pharmacy Department of Biopharmaceutical Sciences, and Comprehensive Sickle Cell Center

820 S. Wood St., Suite 172 (MC 712),

Chicago, IL 60612-7350

Jesse Brown VA Medical Center, Chicago, IL 60612; Email: remoloki@uic.edu

This work was supported by the National Institutes of Health [grant number R01HL078536].

Keywords: pain, acute care center, emergency department, sickle cell disease, opioid, hospital admission 


\begin{abstract}
Background: Acute care units (ACUs) with focused sickle cell disease (SCD) care have been shown to effectively address pain and limit hospitalizations compared to emergency departments (ED), the reason for differences in admission rates is understudied. Our aim was compare effects of usual care for adult SCD pain in ACU and ED on opioid doses and discharge pain ratings, hospital admission rates and lengths of stay.
\end{abstract}

Methods: In a retrospective, comparative cohort, single academic tertiary center study, 148 adults with sickle cell pain received care in the ED, ACU or both. From the medical records we documented opioid doses, unit discharge pain ratings, hospital admission rates, and lengths of stay.

Findings: Pain on admission to the ED averaged $8.7 \pm 1.5$ and to the ACU averaged $8.0 \pm 1.6$. The average pain on discharge from the ED was $6.4 \pm 3.0$ and for the ACU was $4.5 \pm 2.5 .70 \%$ of the 144 ED visits resulted in hospital admissions as compared to $37 \%$ of the 73 ACU visits. Admissions from the ED or ACU had similar inpatient lengths of stay. Significant differences between ED and ACU in first opioid dose and hourly opioid dose were noted.

Conclusions: Applying guidelines for higher dosing of opioids for acute painful episodes in adults with SCD in ACU was associated with improved pain outcomes and decreased hospitalizations, compared to ED. Adoption of this approach for SCD pain in ED may result in improved outcomes, including a decrease in hospital admissions.

Keywords: pain, acute care unit, emergency department, sickle cell disease, opioid, hospital admission 


\section{INTRODUCTION}

\subsection{Background}

Sickle cell disease (SCD) is caused by a point mutation of the $\beta$-globin gene, causing a valine to replace glutamic acid at position 6. As a result, when sickle hemoglobin is deoxygenated, it is able to polymerize into stiff rod like fibers within the red blood cell, causing its shape to be distorted, and on light microscopy may have the appearance of a sickle. In addition to the shape change, it causes the lysis of red cells, impairs blood flow, causing ischemia, and many other physiological changes, including the hallmark characteristic of the disease: pain.

The majority of the estimated 100,000 people in the U.S. living with SCD experiencing severe acute pain episodes go to an emergency department (ED) for care[1-3]. Uncontrolled, severe pain is the most common reason for more than 225,000 ED visits annually, and is the leading cause for admission to the hospital for those with SCD[4-8]. In the U.S. alone, the annual combined ED and inpatient charges for SCD have been estimated to be \$2.4 billion[9].

In some hospitals patients are able to go to specialized acute care units (ACUs) for SCD[9]. Patients cared for in these ACUs have a much lower hospital admission rate than those cared for in an $\operatorname{ED}[10,11]$. However, the reason for the difference in admission rates between these two types of units has not been well explored.

\subsection{Goal of this Study}

We were not able to find any studies that quantified the opioid doses given in an ED compared to an ACU, which if different, may help explain the differences in admission rates, and could help establish new treatment guidelines for SCD. The aim of our study was to compare effects of usual care for SCD pain of adults in the ACU and the ED of the same hospital on 
opioid doses, ACU and ED discharge pain ratings, hospital admission rates and lengths of stay. We hypothesized that opioid doses would be higher for patients receiving usual care in the ACU than in the ED and that pain ratings at discharge, hospital admission rates, and lengths of stay would be lower for patients receiving care in the ACU than the ED.

\subsection{METHODS}

\subsection{Design}

We conducted a retrospective, paired (when available) comparative cohort study. We abstracted from the electronic medical record data for all pain-related visits to the ED and ACU by subjects with SCD during the 2 years of study participation. From this abstracted dataset, we then extracted data for only the first visit to the ED and the first visit to the ACU for each patient. The study protocol was approved by the (blinded) Institutional Review Board.

\subsection{Setting}

The ED and ACU are both part of the Blinded Hospital and Health Sciences System. The ED is the hospital's 24-hour Emergency Department. The ACU is independent of the ED and managed by separate administrators. The ACU is located within the Sickle Cell Clinic of the Blinded Hospital, and established as an alternative to the ED but open 8 am to $5 \mathrm{pm}$, Monday through Friday, during the study period. Patients admitted to the ACU are those with uncomplicated pain crises who are unable to manage their pain at home. The ACU healthcare providers have expertise managing SCD pain crises. Since the ACU is located within the Sickle Cell Clinic, patients have ready access to their regular physicians with SCD expertise. Patients experiencing complicated pain crises (e.g., severe chest pain or headache, fever, crisis due to pregnancy, among others) are not admitted to the ACU and must be evaluated and treated in the ED. Patients who require pain crisis care after the hours of the ACU are admitted to the ED. 


\subsection{Sample}

The study subjects were patients who received their care at the (blinded) Sickle Cell

Clinic. Subjects met the following criteria: 1) age 18 years or older, 2) diagnosis of SCD, 3)

English speaking, 4) consented to participate in a SCD pain study, and 5) received care from the ED or ACU during the 2-years of their participation in the SCD pain study.

The sample of 148 subjects was nearly two-thirds female, and the mean age of the sample was $35.1 \pm 11.9$ years. Table 1 presents the demographic characteristics of the subjects. From Table 1, we observed that there were no significant demographic differences between subjects utilizing the ED only, ACU only, or both ED and ACU.

\subsection{Procedure}

Trained by the $\mathrm{PhD}$ prepared principal investigator $(\mathrm{PI})$ and supervised by a $\mathrm{PhD}$ prepared project director, two reviewers, a research assistant and an expert research nurse, extracted data from the subjects' electronic medical records. The abstracted data included the reason for the visit, presence of pain, medications administered, and pain intensity values (called pain hereafter) at admission and discharge, which the clinical staff obtained using a 0-10 verbal scale, with 0 as no pain and 10 as worst pain. Specifically, the medication data included the analgesic drugs, doses, and routes for the first and subsequent doses administered during ED and ACU visits. We also collected the ACU and ED admission and discharge times and disposition and the hospital admission and discharge dates. In 5 occasions (2 for ACU and 3 for ED), patients discharged home returned to ED on the same day or the next day. In all 5 occasions, the patient was admitted to hospital. These hospitalizations were attributed to the corresponding ACU or ED visit. 
Inter-rater reliability of the data abstraction was assessed by a third reviewer, another $\mathrm{PhD}$ prepared nurse researcher who was also trained by the PI. The third reviewer completed independent extraction of the data for $10 \%$ of the 1,281 ED and ACU visits, which were randomly selected by the study statistician and were unknown to the first two reviewers. The study statistician calculated the inter-rater reliability of the data abstraction, which was $92 \%$. At the time of the data abstraction, all three reviewers were blind to the study goals, but they were not blind to the setting of care since they were documenting data for all pain care the subject received during the pain study period.

\subsection{Analysis}

Data analysis was completed using statistical software R. Descriptive statistics (mean, standard deviation, count, and frequency) were obtained for key demographic variables and baseline measures. Fisher's tests and ANOVA were used to compare demographics of patients visiting ED exclusively, ACU exclusively, and both. To compare patient outcomes between ED and ACU, we performed mixed-effect regression of patient outcomes using initial pain and setting as predictors. We used a subject-specific random effect term to account for the overlap of subjects between two study settings. The amount of missing data was minimal $(<1 \%)$. For missing data processing, we utilized multiple imputation to generate multiple completed datasets, upon which inference was performed and then aggregated.

We utilized two approaches to examine the dosage of opioids that subjects received. In our first approach, we converted all dosages into intravenous (IV) morphine sulfate equivalent (IVMSEQ) values, by equating a $1 \mathrm{mg}$ hydromorphone dose with a $5 \mathrm{mg}$ morphine dose. This conversion enables comparison of the dosages of subjects given different drugs. In our second approach, we compared the first and hourly opioid doses received by a subject against the 
recommended dose levels for morphine and hydromorphone and classified the dosages into four levels: below standard $0.05 \mathrm{mg} / \mathrm{kg} / 2 \mathrm{hr}$ of morphine $(<0.01 \mathrm{mg} / \mathrm{kg} / 2 \mathrm{hr}$ for hydromorphone);

standard dosing $0.05-0.1 \mathrm{mg} / \mathrm{kg} / 2 \mathrm{hr}$ for morphine $(0.01-0.015 \mathrm{mg} / \mathrm{kg} / 2 \mathrm{hr}$ for hydromorphone)[12]; augmented $0.1-0.15 \mathrm{mg} / \mathrm{kg} / 2 \mathrm{hr}$ of morphine $(0.015-.0 .025 \mathrm{mg} / \mathrm{kg} / 2 \mathrm{hr}$ of hydromorphone)[13]; and enhanced $>0.15 \mathrm{mg} / \mathrm{kg} / 2 \mathrm{hr}$ of morphine $(0.025 \mathrm{mg} / \mathrm{kg} / 2 \mathrm{hr}$ of hydromorphone). For a subject receiving both morphine and hydromorphone, we classified their opioid dosage level based on the dominant opioid they received.

\subsection{RESULTS}

\subsection{Pain at Admission and Discharge}

Appearing in Table 2 are the statistics for pain scores at admission to, and discharge from the two study settings. The initial admission pain (called initial pain hereafter) for the ED visits

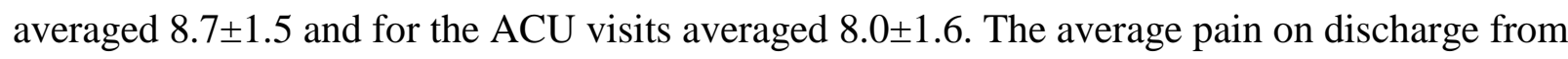
the ED was $6.4 \pm 3.0$ whereas for the ACU the average pain on discharge was $4.5 \pm 2.5$. Whereas the average initial pain for the ED was slightly (0.7 point) higher than the ACU; at discharge however, the gap grew to a 1.9-point difference. The plot of initial pain versus discharge pain for these two settings (Figure 1) clearly shows that given the same initial pain, an ED subject often had much higher pain at discharge than an ACU subject.

The estimated coefficients in Table 3 show that both initial pain and setting were highly statistically significant $(\mathrm{p}<.001)$. Not surprisingly, a higher initial pain predicted a higher discharge pain. The contrast between the two settings confirmed what we observed in Figure 1 with an ED subject having a discharge pain 1.34 points higher than an ACU subject on average given the same initial pain. 


\subsection{Hospital Admissions and Inpatient Length of Stay (LOS)}

The subject's pain at discharge determined whether a subject needed to be admitted to the hospital. In our study sample, subjects with discharge pain greater than 5 were admitted to the hospital $82 \%$ (82\% in ED and $84 \%$ in $\mathrm{ACU}$ ) of the time, whereas those with lower discharge pain were only admitted $25 \%$ (40\% in ED and $13 \%$ in ACU) of the time. Among those admitted into the hospital after first going to ED, the LOS was $8.8 \pm 7.4$ for patients with high discharge pain and 8.0 \pm 5.3 for those with low $(<=5)$ discharge pain. For patients that went to ACU, the LOS was $5.7 \pm 2.8$ and $10.3 \pm 6.2$, respectively.

The results of the hospital admission and LOS also appear in Table 2 . About $70 \%$ of the $144 \mathrm{ED}$ visits resulted in the subjects being admitted to the hospital, whereas $37 \%$ of the $73 \mathrm{ACU}$ visits resulted in the subjects being admitted to the hospital. Subjects who were admitted from the ED or ACU had similar average inpatient lengths of stay. More specifically, average LOS for an admitted ED subject was $8.7 \pm 7.1$ days while that of an admitted ACU subject was $9.3 \pm 5.9$ days. We applied a mixed-effect regression model using ED or ACU initial pain and setting as predictors to examine the setting difference in hospital admission rates and LOS. The parameter estimates in Table 3 showed that controlling for initial pain, a subject going to ED had a significantly higher (odds ratio $=\exp (1.42)=4.1, \mathrm{p}<.001)$ chance of being admitted to a hospital than a subject going to ACU. In contrast to the hospitalization rate, we did not find significant associations between the LOS (for those admitted to a hospital) and setting $(\mathrm{p}=.36)$.

\subsection{Medications}

Table 2 also shows the results of the comparisons of type of medications administered and opioid dosages in the ED and ACU. In the ED, $67 \%$ of the subjects were given morphine first, $28 \%$ received hydromorphone first, and the remaining 5\% did not receive any opioids. For 
the ACU, $74 \%$ of the subjects were first given morphine and $26 \%$ of the subjects were first given hydromorphone. The statistics of hourly morphine and hydromorphone dosages (for those receiving each drug) showed that ACU subjects were given higher dosages.

\subsection{IVMSEQ Analysis}

The mean and standard deviation (SD) of first, total, and hourly dosage received for subjects during visits to ED and ACU appear in Table 2. We observed that ACU had higher values for all three dosage indicators.

Applying a linear mixed effect model to the first dosage, we found that controlling for initial pain, an ACU subject received a significantly higher (2.52 mg IVMSEQ, p<.001, Table 3) first dose than an ED subject. For a subject with an initial pain of 8, a difference of $2.52 \mathrm{mg}$ IVMSEQ corresponds to a $40 \%$ dosage difference. Somewhat surprisingly, the subject's initial pain seemed to only have a minor effect on the first dosage: a 1-point increase in initial pain was associated with only a $0.30 \mathrm{mg}$ IVMSEQ increase in first dosage $(\mathrm{p}=.14)$.

We also analyzed the total IVMSEQ dosage given to subjects during their entire visit since dosages most likely would increase as the visit length increased. We also expected IVMSEQ dosages would be different in the two settings, given that ACU appeared to be more aggressive in medicating. Therefore, we examined the initial pain and setting effects and the rates at which the total IVMSEQ dosages increased with the visit length in each setting. The coefficient estimates in Table 3 confirm that in both settings, the total IVMSEQ dosage increased significantly with time (2.26 mg IVMSEQ/hr, $\mathrm{p}<.001$ for ED and $5.19 \mathrm{mg}$ IVMSEQ/hr, $\mathrm{p}=.002$ for ACU). Again, the initial pain was not strongly associated with the total dosage (1.04 mg IVMSEQ/1-point, $\mathrm{p}=.30$ ). The ACU subject received a significantly higher IVMSEQ total dosage (10.68 mg higher for a visit of 5 hours, a typical visit length, $\mathrm{p}=.004)$. 
A similar model was used to analyze the hourly dosage in the two settings. Initial pain was significantly associated with the hourly dosage (0.31 mg IVMSEQ/hr/1-point, $\mathrm{p}=.04)$. The ACU was significantly higher than ED in hourly dosage, too (1.75 mg IVMSEQ/hr, p<.001). 3.5 Dosage Level Analysis

The dosage level statistics shown in Table 2 again confirm that in the ACU there was more aggressive prescribing of opioids, with a much lower percentage of subjects receiving a below standard dose, and much higher percentage of subjects receiving either augmented or enhanced levels of opioids, compared with ED. Furthermore, none of the subjects required naloxone. The regression outcomes in Table 3 show that the differences between ED and ACU first dosage levels and hourly dosage levels were highly significant $(\mathrm{p}=.004$ and $\mathrm{p}<.001$, respectively).

\subsection{DISCUSSION}

The findings of this retrospective usual care study of the opioid doses given to subjects with SCD experiencing acute pain episodes in the ED compared to the ACU are impressive. Controlling for the subjects' pain scores at admission, those who were cared for in the ACU were treated with significantly higher first, hourly, and total IVMSEQ doses compared to the ED. Those subjects who were treated in the ACU were treated with doses of medication that were more consistent with published guidelines for the management of painful episodes in $\operatorname{SCD}[11,13]$. It should be pointed out that none of the subjects required naloxone reversal. The hospitalization rate and discharge pain were significantly lower in the ACU than the ED. Although some authors have reported that those admitted to the hospital from an ACU had a shorter LOS[11], we did not find the difference to be statistically significant in our study. 
Recommendations for dosing of opioids in SCD for acute pain episodes have been published by several groups $[13,15]$. There is, however, a lack of clinical data showing either the effectiveness, or lack of effectiveness, of these doses.

Our findings are observational but show the difference in pain and admission between two settings, with one setting (ACU in this study) more consistently applying the guidelines for higher $\mathrm{mg} / \mathrm{kg}$ doses of morphine or hydromorphone for management of acute pain episodes of SCD. We grouped patients into one of four $\mathrm{mg} / \mathrm{kg}$ treatment groups (below standard, standard, augmented, and enhanced). This weight-based dosing allows for a more personalized medication approach, when treatments include hydrophilic drugs such as morphine or hydromorphone, than categorizing patients into those weighing less than 50kg or more. Using this approach, we found that in the ED 54\% of patients received either a below standard or standard first dose, whereas in the ACU only $37 \%$ received either of these doses. Conversely, in the ED only $15 \%$ of patients received an augmented hourly dose and $24 \%$ were treated with an enhanced dose, whereas in the ACU, more than twice (32\%) as many received an augmented dose and 34\% were treated with an enhanced dose.

Both settings used morphine as the first-choice drug, so drug selection is not the likely explanation for the larger IVMSEQ doses used in the ACU. Surprisingly though, the subject's initial pain seemed to have only a minor effect on the first dose (a 1-point increase in the initial pain was associated with only a 0.30mg IVMSEQ increase of the first dose). In the ACU, where the staff were trained in treatment of SCD pain, after the response to the first dose was assessed, patients received more than twice as large hourly doses over time (5.19 IVMSEQ/hr) than in the ED (2.26 mg IVMSEQ/hr). Therefore, we conclude that the ACU clinicians were more 
aggressive than ED clinicians in prescribing larger opioid doses, a safe practice since no patients required naloxone reversal.

Implementing more effective approaches for controlling acute pain episodes of SCD are urgently needed to improve patients' quality of life and care, decrease the need for healthcare utilization including hospital admissions, and lower medical costs. In 1985, Grady Memorial Hospital in Atlanta opened a specialized, 24-hour unit to care for SCD patients who were having acute pain episodes that they could not control at home, instead of having to use its very busy $\mathrm{ED}[27]$. Due to its dramatic success in decreasing hospital admission rates, similar units have been established throughout the world for adults as well as children with SCD. Although there is a wide variation in their operation, they appear to universally reduce admission rates to the hospital[10, 13, 28-30] and demonstrate substantial savings[11]. Some have shown a decrease in the inpatient length of stay as well[11]. There are several reasons suggested to explain the success of these specialized units caring only for those with SCD including having staff who choose to and enjoy working with SCD patients on a regular basis, and quicker administration of pain medication. Unfortunately, most people with SCD do not have access to these units, and it would be difficult to implement ACUs universally. However, this study reveals significant differences in the dosing of opioid therapy between the ACU and ED. If larger opioid doses were implemented in the ED for control of SCD pain, it is possible that it would help improve patient care, including a decrease in hospital admissions.

There are limitations to our study. It is important to note that the ACU provided care for patients with uncomplicated pain crises, whereas the ED could have had patients with more complicated pain episodes, which may have contributed to the higher hospital admission rate of patients admitted from the ED. Because this study was a retrospective observational study with 
medical record review, evidence generated is less generalizable than a prospective double-blind randomized controlled trial. Other limitations may have included confounding patient, provider, or environmental determiners that, at the time of patient care, were not known or measured. Also, medical record reviewers were not blinded to setting of care, which could have led to biasing of results[31, 32]. The high inter-rater reliability rate $(92 \%)$ on $10 \%$ of visits randomly selected, however, provides evidence of minimal abstraction bias.

\subsection{CONCLUSIONS}

Our analysis of practice-based electronic health record data generated important insights about management of acute pain episodes for adults with SCD. Applying guidelines for higher dosing of opioids for acute pain episodes of SCD in the acute care setting was associated with less pain and decreased hospitalization. Adoption of this approach for the treatment of sickle cell pain in the ED may result in improved patient care, including a decrease in hospital admissions. Although not every ED has the resources to have SCD specialists readily available for pain care, most all EDs have sufficient resources to systematically and carefully increase opioid doses to those that provide adequate pain control for adults with SCD and thereby reduce hospital admissions. A prospective randomized controlled trial of guideline-based dosing of opioids for acute pain episodes of SCD is warranted to test the generalizability of our observational findings to additional settings. 


\section{Acknowledgements:}

The contents of this publication are solely the responsibility of the authors and do not necessarily represent the official views of the National Heart Lung and Blood Institute. The final peerreviewed manuscript is subject to the National Institutes of Health Public Access Policy. The authors thank the patients with sickle cell disease for participating in this study, the staff at the Comprehensive Sickle Cell Center for their continuous support of the study, and the following individuals for their help in data collection: HXXXXXX WXXXXX and JXXXX CXXXXX. The authors declare no conflicts of interest. Dr. XXXXXX is Chairman and Founder of

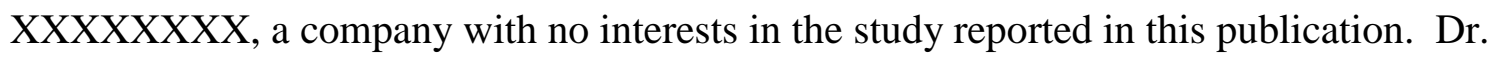
XXXXXX conducted the data analysis and had full access to the data as did Dr. XXXXX; both take full "responsibility for the integrity of the data and the accuracy of the data analysis." This study received initial IRB approval at the XXXXX on May 9, 2006, and has been under continuous IRB approval until the present. 
References

[1] Yusuf HR, Atrash HK, Grosse SD, Parker CS, Grant AM. Emergency department visits made by patients with sickle cell disease: a descriptive study, 1999-2007. Am J Prev Med. 2010;38:S536-41.

[2] Shankar SM, Arbogast PG, Mitchel E, Cooper WO, Wang WC, Griffin MR. Medical care utilization and mortality in sickle cell disease: a population-based study. Am J Hematol. 2005;80:262-70.

[3] Raphael JL, Dietrich CL, Whitmire D, Mahoney DH, Mueller BU, Giardino AP. Healthcare utilization and expenditures for low income children with sickle cell disease. Pediatr Blood Cancer. 2009;52:263-7.

[4] Yusuf HR, Atrash HK, Grosse SD, Parker CS, Grant AM. Emergency department visits made by patients with sickle cell disease: a descriptive study, 1999-2007. Am J Prev Med. 2010;38:S536-S41.

[5] Ballas SK. Sickle Cell Pain. 1 edition ed. Seattle: IASP Press; 1998.

[6] Ballas SK, Gupta K, Adams-Graves P. Sickle cell pain: a critical reappraisal. Blood. 2012;120:3647-56.

[7] Wilkie DJ, Molokie R, Boyd-Seal D, et al. Patient-reported outcomes: descriptors of nociceptive and neuropathic pain and barriers to effective pain management in adult outpatients with sickle cell disease. J Natl Med Assoc. 2010;102:18-27.

[8] Ezenwa MO, Molokie RE, Wang ZJ, et al. Safety and Utility of Quantitative Sensory Testing among Adults with Sickle Cell Disease: Indicators of Neuropathic Pain? Pain Pract. 2015:n/a-n/a.

[9] Lanzkron S, Carroll CP, Haywood C. The burden of emergency department use for sickle - cell disease: An analysis of the national emergency department sample database. Am J Hematol. 2010;85:797-9.

[10] Adewoye AH, Nolan V, McMahon L, Ma Q, Steinberg MH. Effectiveness of a dedicated day hospital for management of acute sickle cell pain. Haematologica. 2007;92:854-.

[11] Benjamin LJ, Swinson GI, Nagel RL. Sickle cell anemia day hospital: an approach for the management of uncomplicated painful crises. Blood. 2000;95:1130-6.

[12] Tesler MD, Wilkie DJ, Holzemer WL, Savedra MC. Postoperative analgesics for children and adolescents: prescription and administration. J Pain Symptom Manage. 1994;9:85-95.

[13] Benjamin L, Dampier C, Jacox A, et al. Guideline for the management of acute and chronic pain in sickle cell disease. Glenview, IL: American Pain Society. 1999.

[14] Farrar JT, Young JP, LaMoreaux L, Werth JL, Poole RM. Clinical importance of changes in chronic pain intensity measured on an 11-point numerical pain rating scale. Pain.

2001;94:149-58.

[15] Solomon LR. Pain management in adults with sickle cell disease in a medical center emergency department. J Natl Med Assoc. 2010;102:1025-32.

[16] Marco CA, Kanitz W, Jolly M. Pain scores among emergency department (ED) patients: comparison by ED diagnosis. The Journal of emergency medicine. 2013;44:46-52.

[17] Darbari DS, Neely M, van den Anker J, Rana S. Increased clearance of morphine in sickle cell disease: implications for pain management. The Journal of Pain. 2011;12:531-8. 
[18] Shord SS, Cavallari LH, Gao W, et al. The pharmacokinetics of codeine and its metabolites in Blacks with sickle cell disease. European journal of clinical pharmacology. 2009;65:651-8.

[19] Hooten WM, Bruce BK. Beliefs and attitudes about prescribing opioids among healthcare providers seeking continuing medical education. Journal of opioid management. 2010;7:417-24.

[20] Hwang CS, Turner LW, Kruszewski SP, Kolodny A, Alexander GC. Prescription drug abuse: a national survey of primary care physicians. JAMA internal medicine.

2015;175:302-4.

[21] Dowell D, Haegerich TM, Chou R. CDC guideline for prescribing opioids for chronic pain-United States, 2016. JAMA. 2016;315:1624-45.

[22] Todd KH, Deaton C, D'Adamo AP, Goe L. Ethnicity and analgesic practice. Annals of emergency medicine. 2000;35:11-6.

[23] Barr DA. Health disparities in the United States: Social class, race, ethnicity, and health: JHU Press; 2014.

[24] Zempsky WT, Corsi JM, McKay K. Pain scores: are they used in sickle cell pain? Pediatric emergency care. 2011;27:27-8.

[25] OM I. Relieving Pain in America: A Blueprint for Transforming Prevention, Care. Education, and Research Washington, DC: Institute of Medicine. 2011.

[26] Nelson AR, Stith AY, Smedley BD. Unequal treatment: confronting racial and ethnic disparities in health care (full printed version): National Academies Press; 2002.

[27] Platt A, Eckman JR, Beasley J, Miller G. Treating sickle cell pain: an update from the Georgia Comprehensive Sickle Cell Center. Journal of Emergency Nursing. 2002;28:297303.

[28] Wright J, Bareford D, Wright C, et al. Day case management of sickle pain: 3 years experience in a UK sickle cell unit. British journal of haematology. 2004;126:878-80.

[29] Ware MA, Hambleton I, Ochaya I, Serjeant GR. Day - care management of sickle cell painful crisis in Jamaica: a model applicable elsewhere? British journal of haematology. 1999;104:93-6.

[30] Raphael JL, Kamdar A, Beavers MB, Mahoney DH, Mueller BU. Treatment of uncomplicated vaso - occlusive crises in children with sickle cell disease in a day hospital. Pediatr Blood Cancer. 2008;51:82-5.

[31] Gilbert EH, Lowenstein SR, Koziol-McLain J, Barta DC, Steiner J. Chart reviews in emergency medicine research: Where are the methods? Ann Emerg Med. 1996;27:305-8. [32] Kaji AH, Schriger D, Green S. Looking through the retrospectoscope: reducing bias in emergency medicine chart review studies. Ann Emerg Med. 2014;64:292-8. 
Table 1. Demographic Characteristics of Participants Receiving Care in the Emergency Department (ED), Acute Care Unit (ACU) or Both Settings (N=148)

\section{Overall Both ED Only ACU Only p Value}

\section{Gender}

Male

$52(35 \%) \quad 22(32 \%) \quad 29(39 \%) \quad 1(25 \%) \quad .67$

Female

$96(65 \%) \quad 47(68 \%) \quad 46(61 \%) \quad 3(75 \%)$

SC Type

$\mathrm{Hb} \mathrm{SS}$

$$
110(74 \%) \quad 49(71 \%) \quad 59(79 \%) \quad 2(50 \%)
$$

$\mathrm{Hb} \mathrm{SC}$

$21(14 \%) \quad 10(14 \%) \quad 10(13 \%) \quad 1(25 \%)$

Other $(\mathrm{SB}+, \mathrm{SBTh}, \ldots) \quad 17(12 \%) \quad 10(14 \%) \quad 6(8 \%) \quad 1(25 \%)$

\section{Race/Ethnicity}

$\begin{array}{cllllll}\text { Race } & \text { White } & 2(1 \%) & 2(3 \%) & 0(0 \%) & 0(0 \%) & \\ \text { Black } & 145(98 \%) & 66(96 \%) & 75(100 \%) & 4(100 \%) & .18 \\ \text { Mixed } & 1(1 \%) & 1(1 \%) & 0(0 \%) & 0(0 \%) & \\ \text { Ethnicity } & \text { Hispanic } & 5(3 \%) & 2(3 \%) & 3(4 \%) & 0(0 \%) & 1 \\ \text { Non-Hispanic } & 143(97 \%) & 67(97 \%) & 72(96 \%) & 4(100 \%) & \\ \text { Age, mean (SD) } & 35.1(11.9) & 34.8(11.7) & 35.0(12.2) & 40.5(11.0) & .65\end{array}$


Table 2. Pain Ratings, Hospital Admission Rates, Length of Stay (LOS) and Medication by Emergency Department (ED) and Acute Care Unit (ACU)

\begin{tabular}{|c|c|c|c|}
\hline & & $\operatorname{ED}(N=144)$ & $\operatorname{ACU}(\mathrm{N}=73)$ \\
\hline \multirow[t]{2}{*}{ Pain Rating } & Initial Pain, mean (SD) & $8.7(1.5)$ & $8.0(1.6)$ \\
\hline & Discharge Pain, mean (SD) & $6.4(3.0)$ & $4.5(2.5)$ \\
\hline \multirow[t]{2}{*}{ Hospitalization } & Admission, $\mathrm{n}(\%)$ & $101(70 \%)$ & $27(37 \%)$ \\
\hline & $\mathrm{LOS}^{*}$, mean $(\mathrm{SD})$ & $8.7(7.1)$ & $9.3(5.9)$ \\
\hline \multirow[t]{3}{*}{ First Opioid } & Morphine, n (\%) & $97(67 \%)$ & $54(74 \%)$ \\
\hline & Hydromorphone, n (\%) & $40(28 \%)$ & $19(26 \%)$ \\
\hline & No Opioid, n (\%) & $7(5 \%)$ & $0(0 \%)$ \\
\hline Morphine Dose & Hourly, Mean (SD), mg/hr & $2.8(2.6)$ & $4.0(2.3)$ \\
\hline Hydromorphone Dose & Hourly, Mean (SD), mg/hr & $1.0(0.8)$ & $1.5(1.0)$ \\
\hline \multirow[t]{5}{*}{ Opioid Dose } & First Dose, Mean (SD), & $6.8(3.8)$ & $9.2(5.4)$ \\
\hline & IVMSEQ & & \\
\hline & Total, Mean (SD), IVMSEQ & $19.5(21.0)$ & $33.6(27.2)$ \\
\hline & Hourly, Mean (SD), & $3.8(3.5)$ & $5.3(3.8)$ \\
\hline & IVMSEQ/hr & & \\
\hline \multirow[t]{4}{*}{ First Dose } & Below Standard, n (\%) & $27(19 \%)$ & $5(7 \%)$ \\
\hline & Standard, n (\%) & $51(35 \%)$ & $22(30 \%)$ \\
\hline & Augmented, n (\%) & $30(21 \%)$ & $22(30 \%)$ \\
\hline & Enhanced, n (\%) & $36(25 \%)$ & $24(33 \%)$ \\
\hline \multirow[t]{4}{*}{ Hourly Dose } & Below Standard, n (\%) & $46(32 \%)$ & $9(12 \%)$ \\
\hline & Standard, n (\%) & $42(29 \%)$ & $16(22 \%)$ \\
\hline & Augmented, n (\%) & $21(15 \%)$ & $23(32 \%)$ \\
\hline & Enhanced, n (\%) & $35(24 \%)$ & $25(34 \%)$ \\
\hline
\end{tabular}


Table 3. Regression Analysis of Patient Outcomes and Medication

\begin{tabular}{|c|c|c|c|c|c|}
\hline Outcome & Predictor & Estimate & Std Error & $z$ value & p value \\
\hline \multirow[t]{2}{*}{ Discharge Pain } & $\begin{array}{l}\text { Setting } \\
\text { (ref=ACU) }\end{array}$ & 1.34 & 0.35 & 3.86 & $<.001$ \\
\hline & Initial Pain & 0.59 & 0.13 & 4.67 & $<.001$ \\
\hline \multirow[t]{2}{*}{$\begin{array}{l}\text { Hospitalization } \\
\text { Rate }\end{array}$} & $\begin{array}{l}\text { Setting } \\
\text { (ref=ACU) }\end{array}$ & 1.42 & 0.37 & 3.81 & $<.001$ \\
\hline & Initial Pain & 0.22 & 0.12 & 1.87 & .06 \\
\hline \multirow[t]{2}{*}{ LOS } & $\begin{array}{l}\text { Setting } \\
\text { (ref=ACU) }\end{array}$ & -1.00 & 1.07 & -0.94 & .36 \\
\hline & Initial Pain & 0.49 & 0.40 & 1.24 & .23 \\
\hline \multirow[t]{2}{*}{$\begin{array}{l}\text { First Opioid } \\
\text { Dosage }\end{array}$} & $\begin{array}{l}\text { Setting } \\
\text { (ref=ACU) }\end{array}$ & -2.52 & 0.59 & -4.28 & $<.001$ \\
\hline & Initial Pain & 0.30 & 0.20 & 1.51 & .14 \\
\hline \multirow[t]{4}{*}{ Total Dosage } & $\begin{array}{l}\text { Setting } \\
(\text { ref=ACU) }\end{array}$ & -10.68 & 3.53 & -3.03 & .004 \\
\hline & Initial Pain & 1.04 & 1.00 & 1.04 & .30 \\
\hline & $\begin{array}{l}\text { Visit Length } \\
\text { (ED) }\end{array}$ & 2.26 & 0.59 & 3.80 & $<.001$ \\
\hline & $\begin{array}{l}\text { Visit Length } \\
\text { (ACU) }\end{array}$ & 5.19 & 1.57 & 3.31 & .002 \\
\hline \multirow[t]{2}{*}{ Hourly Dosage } & $\begin{array}{l}\text { Setting } \\
\text { (ref=ACU) }\end{array}$ & -1.75 & 0.38 & -4.66 & $<.001$ \\
\hline & Initial Pain & 0.31 & 0.15 & 2.05 & .04 \\
\hline \multirow[t]{2}{*}{$\begin{array}{l}\text { First Dosage } \\
\text { Category }\end{array}$} & $\begin{array}{l}\text { Setting } \\
\text { (ref=ACU) }\end{array}$ & -0.95 & 0.32 & -2.92 & .004 \\
\hline & Initial Pain & 0.11 & 0.11 & 1.03 & .30 \\
\hline \multirow[t]{2}{*}{$\begin{array}{l}\text { Hourly Dosage } \\
\text { Category }\end{array}$} & $\begin{array}{l}\text { Setting } \\
\text { (ref=ACU) }\end{array}$ & -1.34 & 0.34 & -3.96 & $<.001$ \\
\hline & Initial Pain & 0.24 & 0.11 & 2.11 & .03 \\
\hline
\end{tabular}

$\mathrm{ED}=$ Emergency Department, ACU = Acute Care Unit

Dosage Category = Below Standard, Standard, Augmented, Enhanced 
Figure 1.

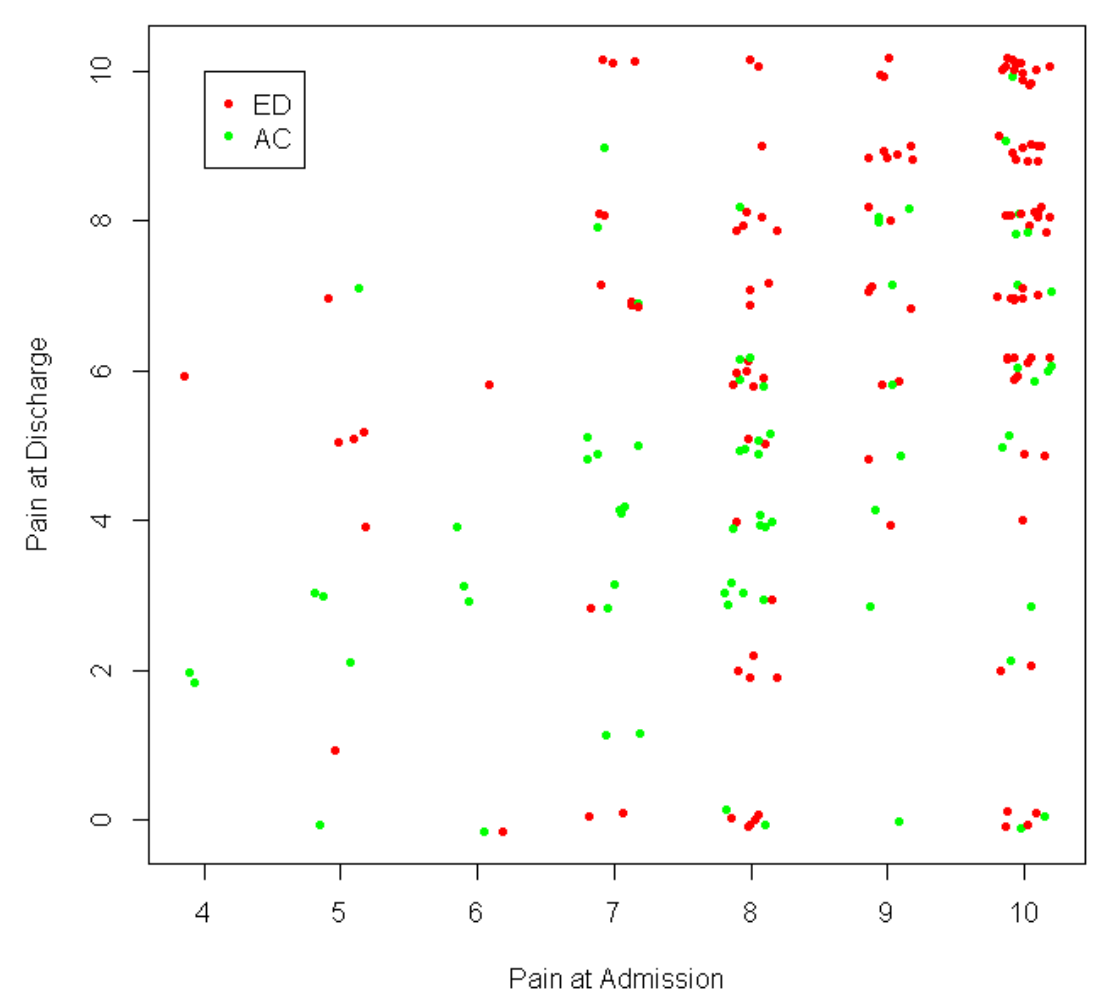

$\mathrm{ED}=$ Emergency Department

$\mathrm{AC}=$ Acute Care Unit

Figure(s) 
Figure(s)
\[ \begin{array}{l}\text { Figure 1. Initial and Discharge Pain Ratings in Two Settings: Emergency Department (ED) and Acute } \\ \text { Care Unit (AC) }\end{array} \]

Figure(s)
$\begin{aligned} & \text { Figure 1. Initial and Discharge Pain Ratings in Two Settings: Emergency Department (ED) and Acute } \\ & \text { Care Unit (AC) }\end{aligned}$

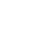

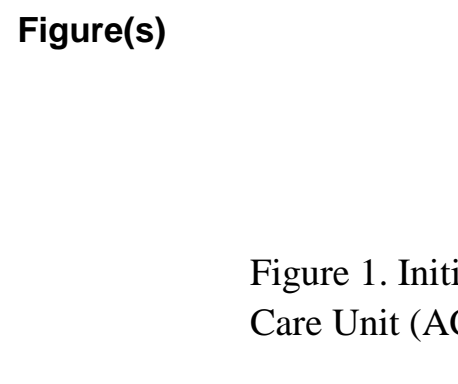

Cons

(1)

(1) (2)

(a)

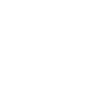

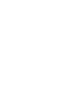
更 更 (1) 